\title{
PROJETOS “ZN:PRDM (ZONA NEUTRA: PASSA UM RIO DENTRO DE MIM)" E "CAIXA DOS HORIZONTES POSSÍVEIS”, DO GRUPO POÉTICAS DIGITAIS
}

Gilbertto Prado

\begin{abstract}
Resumo
O Grupo Poéticas Digitais foi criado em 2002 no Departamento de Artes Plásticas da ECA-USP com a intenção de gerar um núcleo multidisciplinar, promovendo o desenvolvimento de projetos experimentais e a reflexão sobre o impacto das novas tecnologias no campo das artes. O Grupo é um desdobramento do projeto WAwRWT iniciado em 1995 por Gilbertto Prado e tem como participantes artistas, pesquisadores e estudantes. O objetivo deste artigo é apresentar alguns projetos artísticos recentes do grupo: "ZN:PRDM (Zona Neutra: Passa um Rio Dentro de Mim)" de 2013, bem como "Caixa dos Horizontes Possíveis" de 2014.
\end{abstract}

\section{Palavras-chave:}

Instalação Interativa, Artemídia, Arte

Contemporânea, Design, Dispositivos Artísticos.

\section{Introdução: experiência e pertencimento}

Vivre c'est passer d'un espace à l'autre, en essayant le plus possible de ne pas se cogner ${ }^{1}$.

Georges Perec (1974, p. 14)

Muitos dos trabalhos de arte no campo das chamadas "novas mídias" colocam em evidência seu próprio funcionamento, seu estatuto, produzindo acontecimentos e oferecendo processos, se expondo também enquanto potências e condições de possibilidade. Os trabalhos não são somente apresentados para fruição em termos de visualidade, ou de contemplação, mas carregam também outras solicitações para experenciá-los. Outras solicitações de diálogos e de hibridações², em vários níveis e também com outras referências e saberes, incluindo as máquinas programáveis e/ou de feedbacks, inteligência artificial, estados de imprevisibilidade e de emergência controlados por sistemas artificiais numa ampliação do

\section{Abstract}

Poéticas Digitais Group was created in 2002 in the Visual Arts Department at ECA-USP to create a multidisciplinary center, promoting the development of experimental projects and reflection on the impact of new technologies in the field of arts. The Group is an unfolding of the wAwRWT project started in 1995 by Gilbertto Prado and has as participants lecturers, artists, researchers and students. The aim of this article is to present some recent experiments such as "ZN:PRDM" (Neutral Zone: a River Flows Inside Me), from 2013, and "Caixa dos Horizontes Possíveis" (Box of Possible Horizons), from 2014.

\section{Keywords:}

Interactive Installation, Media Art, Digital Art, Contemporary Art, Design, Dispositive.

campo perceptivo, oferecendo modos de sentir expandidos, entre o corpo e as tecnologias, em mesclas do real e do virtual tecnológico, como um atualizador de poéticas possíveis.

A arte tem se constituído como um lugar de trocas e de contaminação e, certamente, nunca foi alheia ao conhecimento científico e técnico. As práticas e processos artísticos têm a capacidade de ajuste de interferências, podendo assumir a entrada de variáveis que vêm do contexto sem que isto tenha que supor a extinção de suas especificidades, mas deve somente aumentar a sua capacidade de absorção e reorganização $A$ arte é um sistema aberto, que também considera a pergunta "e por que não?"3. Porém, entre as dificuldades na realização e agenciamento, poderíamos apontar o uso e o entendimento das estruturas específicas, novas interfaces e dispositivos ${ }^{4}$ e das distintas intervenções poéticas inerentes. Dificuldades também que muitas vezes se iniciam 


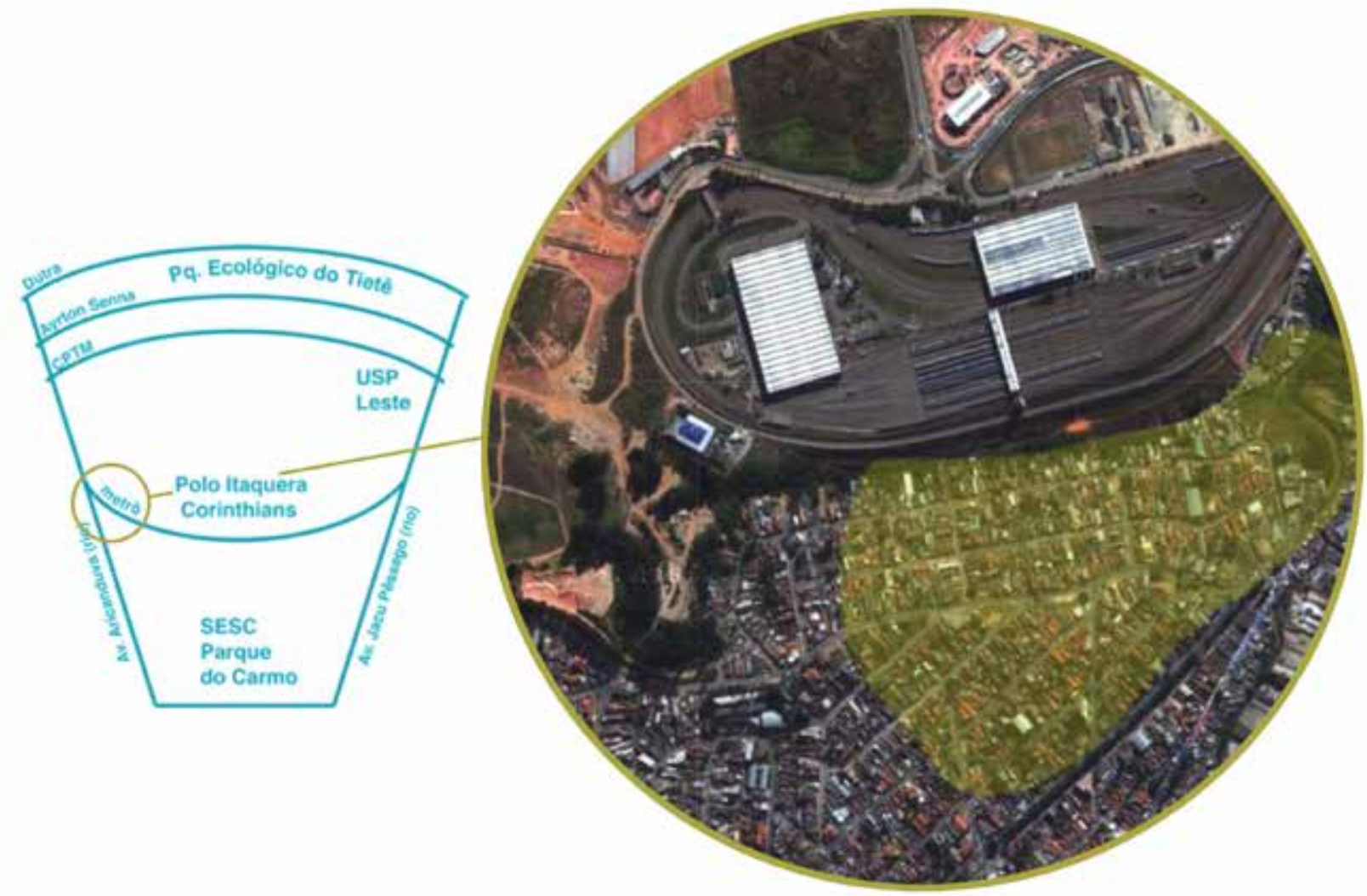

Figura 1 - ZNPRDM - Área escolhida para realização da ação artística na Zona Leste de São Paulo.

no estranhamento do uso de instrumentos digitais e suas lógicas operacionais. Essas dificuldades hoje se diluem, no que diz respeito à utilização, e se tornam recorrentes no uso cotidiano de máquinas, interfaces e utilitários, como computadores, navegadores, DVDs, câmeras digitais, celulares, GPS, caixas de banco, de metrô, de ônibus, sensores de presença etc.

Todavia, os trabalhos artísticos vão além dessas muitas aparências e páginas de código de programação, além dos dispositivos e interfaces e eventuais encantamentos e descobertas. Há também a discussão que eles trazem e a sutileza que eles incorporam, a necessidade desses novos olhares, ouvires, tocares e fazeres em outras conjugações ${ }^{5}$.

Por meio da arte e o uso dos meios digitais em espaço público, podemos desenhar novas experiências em relação às cidades e nossos entornos. Desta forma, pretende-se ativar o desejo, o uso e o sentimento de pertencimento e diálogo nos espaços públicos, não apenas em parques e locais usuais de lazer, mas de uma forma generalizada nos locais de uso cotidiano. Ações como estas pretendem também tornar a rua um local não apenas de passagem funcional, ou seja, do uso exclusivo para ir de um lugar a outro, mas de passagens e convivências sem prévia orientação.

A presença das tecnologias nos espaços de trânsito tem produzido um novo tipo de temporalidade e sociabilidade. Instauram uma nova maneira de perceber os espaços e seus modos de percorrêlos. Geramos uma malha invisível e imaterial produzida pelo atravessamento das tecnologias eletrônicas e digitais nos espaços - não mais como objetos estranhos, mas incorporados e embutidos no ambiente.

É importante remarcar que todos esses novos processos que atestam presença e a influência da tecnologia da comunicação informatizada no cotidiano do cidadão contemporâneo representam novos contextos para a reflexão e o fazer artístico, ganhando inclusive um enorme espaço como público leigo. É todo um imaginário social e artístico que está em jogo e em transformação. Espaços de transição, 


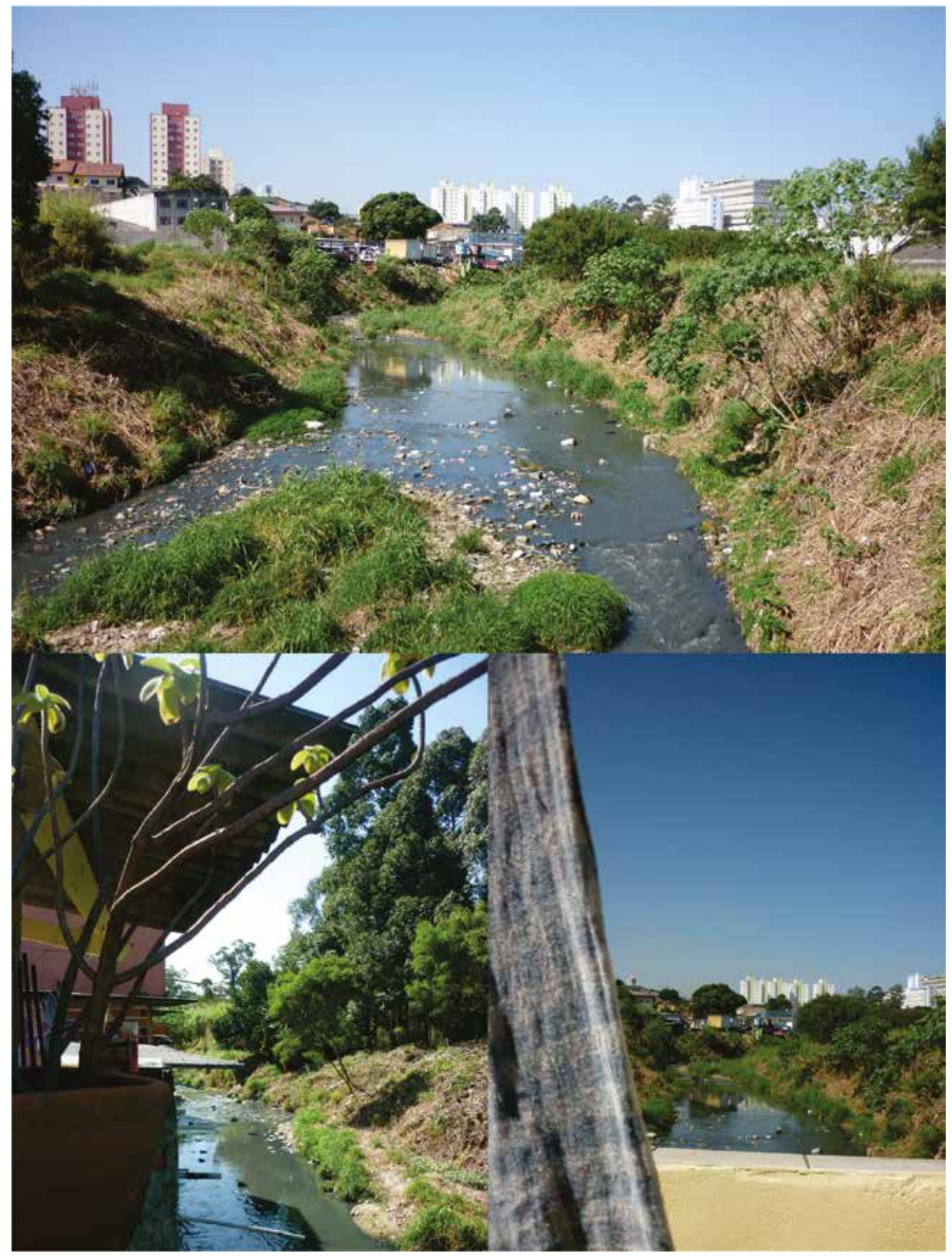

Figura 2 - ZNPRDM - Procurando por curvas remanescentes de rios e cursos de água; Um riacho passando por baixo de uma casa. 

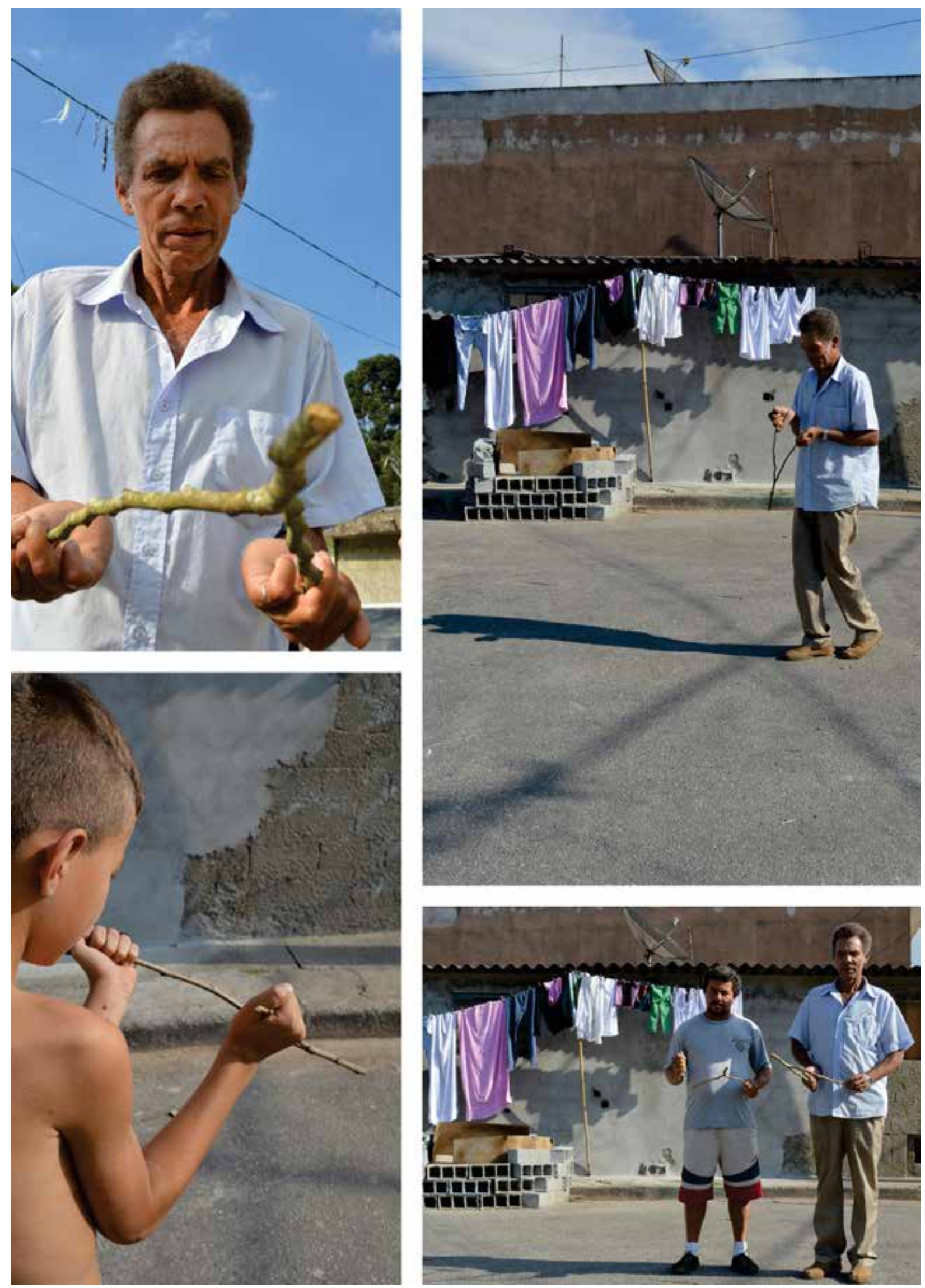

Figura 3 - ZN:PRDM - buscando água a região (dowsing) procurando, percustando. 

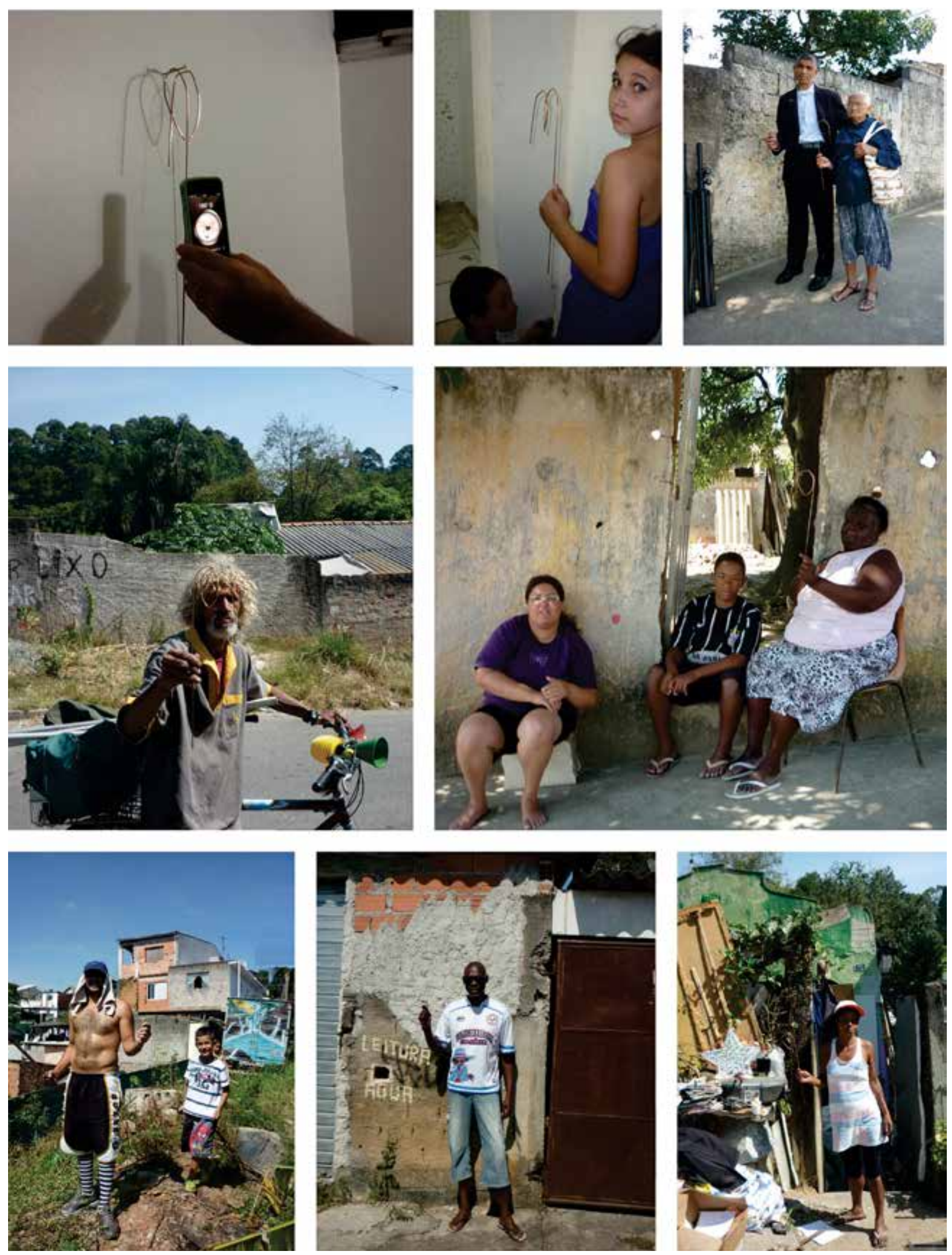

Figura 4 - ZN:PRDM - antena. 

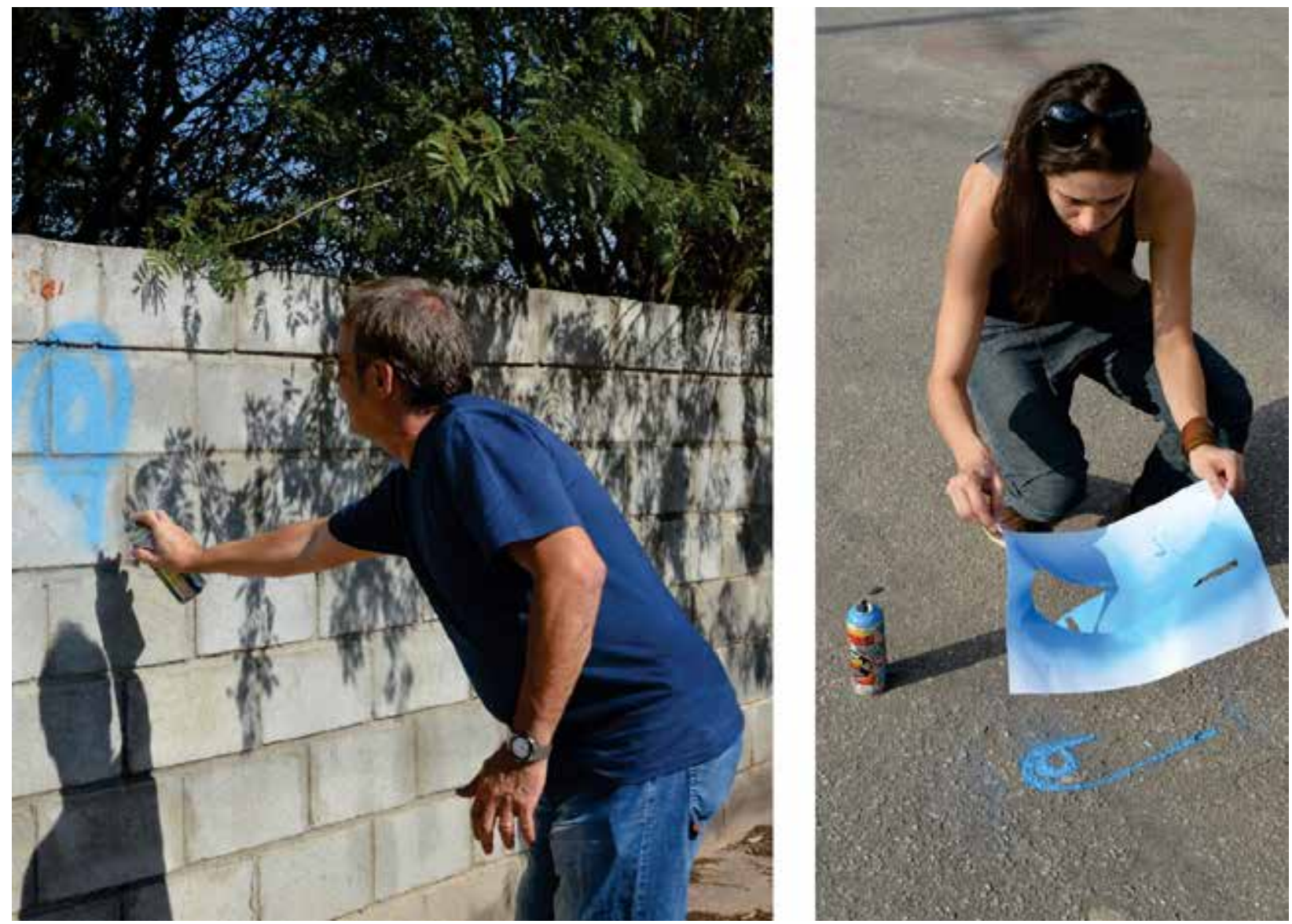

Figura 5 - ZN: PRDM - grafite.

eles funcionam como ativadores ou catalisadores de ações que se seguem e se encadeiam. 0 artista propõe um contexto, uma exploração de relações entre seres e coisas, um quadro sensível em que algo pode ou não ser produzido (PRADO, 2003). $\mathrm{Na}$ medida em que o individuo se move, seu raio de ação de pertencimento pode ser ativado por outros elementos. Então, podemos pensar na permeabilidade destes espaços partilhados, procurando uma abordagem mais poética para a cidade, para permitir a troca, descoberta, criação e experiência, lembrando O'Rourke que "o mapa do ambiente engloba tanto as imediações, físicas e urbanas, e através das nossas próprias percepções e ações como pedestres, e através desses filtros ideológicos e culturais que vemos essa experiência" (O'ROURKE, 2013, p. XVIII). Isso leva o indivíduo a se sentir como pertencente à rua, à praça, aos espaços públicos, independentemente se eles têm ou não grande infraestrutura envolvendo-os em um estado de harmonia e compromisso em suas interações diárias com a cidade.
Uma das intenções dos projetos do Grupo Poéticas Digitais é trazer trabalhos interativos com uma estrutura híbrida, não necessariamente modificáveis com a intervenção direta e imediata do público, mas que suas ações sejam incorporadas em um sistema maior. São acoplamentos de elementos usuais ou cotidianos, como árvores (PRADO, 2013), antenas (ZN:PRDM), com dispositivos e próteses aparentes, mecanismos eletromecânicos, celulares etc., num mesmo conjunto. Pois o público fica sem saber o que fazer, num embate entre o intervir ou não intervir, entre o tocar ou não tocar. Pode ou não pode? (questão essa que permeia nossa vida, que sempre foi híbrida em todos os sentidos, com suas fronteiras, matrizes e matizes).

Creio ainda que esta relação de conjunto/ objeto construído e da quase não ação direta nos sistemas, imprime um "quase" espaço de contemplação em oposto a quase sempre obrigação de ação/intervenção nos ambientes interativos. É nesse "quase" que ficam os ruídos, seja pelos deslumbramentos dos desvios possíveis, 


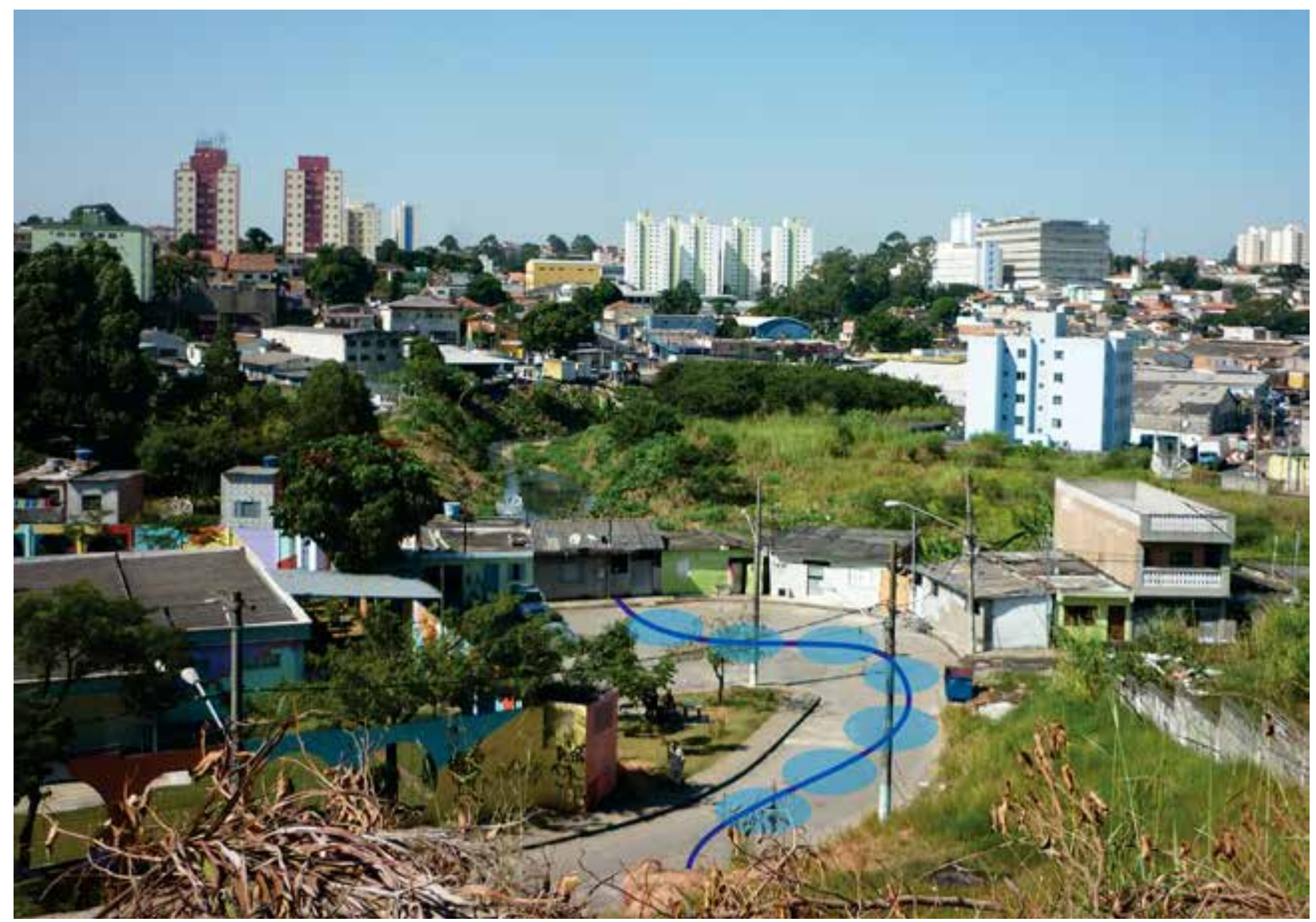

Figura 6 - Zona Neutra: um rio passa por mim. Escutando o som da água que passa bem embaixo dos meus pés.

seja na descoberta poética de diferentes formas de percepção do outro e da nossa complexa posição dentro dessas redes e sistemas.

\section{ZN:PRDM (Zona Neutra: Passa um Rio Dentro de Mim)}

Em "ZN:PRDM", através de distintas marcações e de mapas existentes, buscamos os indícios e sinais de fluxos subterrâneos, além dos ductos de água, esgotos, fios e cabos, garagens, metrô, nos caminhos sobrepostos e retificados das nossas cidades.

O local escolhido para realizar o projeto foi um trecho de periferia carente de recursos da Zona Leste de São Paulo, bairro enorme (298, 8 Km2, 3.620.494 habitantes) e com bolsões de infraestrutura precária e pouco apoio político-governamental.

\subsection{Como ouvir o barulho do rio, que corre bem embaixo dos nossos pés?}

Muitos rios e córregos que serpenteavam pelas cidades já não são mais visíveis (nem audíveis). Por diversas razões, multiplicaram-se tentativas de domá-los, represá-los em caminhos lineares e subterrâneos, ocultos, em longas filas retas de tubos, canaletas e ductos de cimentos, em caminhos retificados que, às vezes de repente, explodem durante as chuvas e cheias, retomando os seus espaços, leitos e caminhos de origem.

Entre as referências para este trabalho, o projeto "Rios \& Ruas" desenvolve processos de conscientização da população sobre os rios canalizados e ocultos na cidade. Luiz de Campos Júnior, um dos idealizadores dessa iniciativa, manifesta sua indignação com o quanto se gasta para esconder um rio, pois se trata verdadeiramente de "um esforço de engenharia absurdo" (CAMPOS JR., 2013) mobilizado para isso, observando que, num espaço urbano como o da capital São Paulo, há uma espécie de inexistência de muitos rios e córregos que, por estarem encobertos e fora de nosso cotidiano, não pertencem ao nosso campo de visão e de percepção.

Para realizar o projeto "ZN:PRDM", lançamos mão de alguns princípios da radiestesia, "técnica 

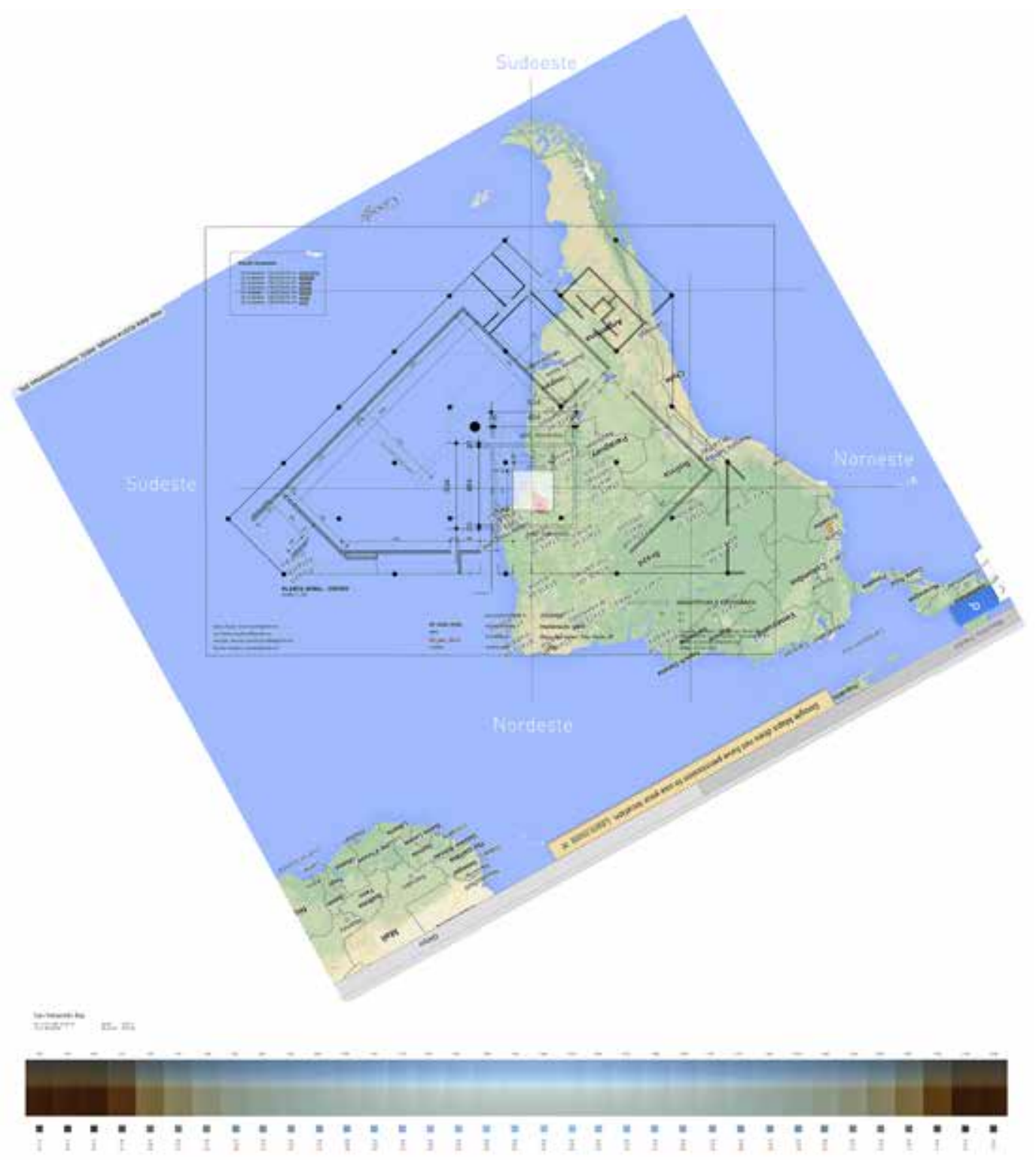

\section{War. $=$}

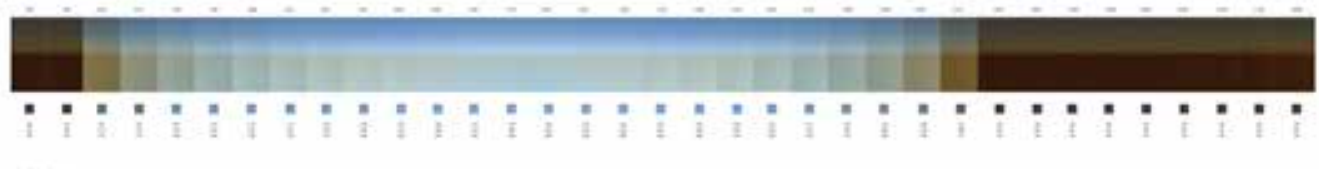

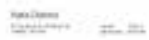

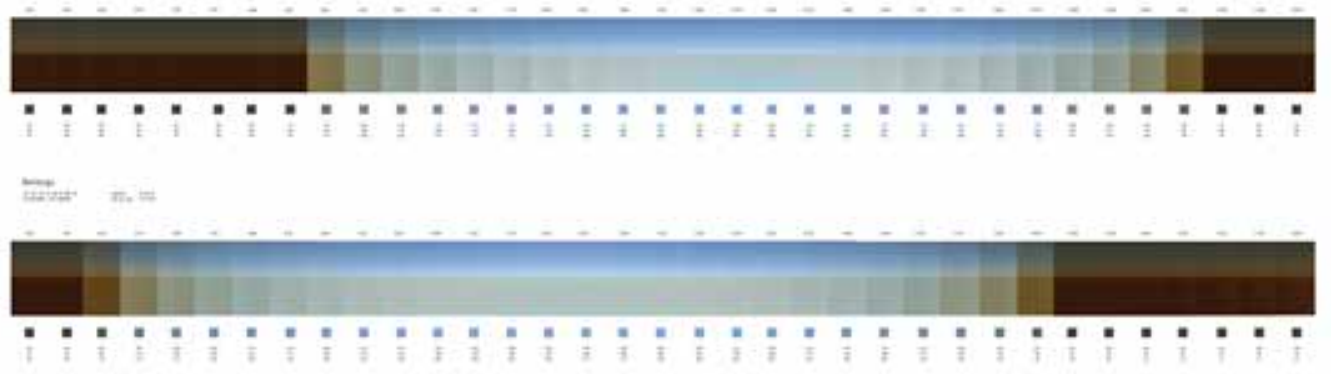

Figura 7 - Posição geográfica relativa do Paço das Artes, no mapa da América do Sul e dos horizontes a serem trabalhados na instalação interativa. Variação da luz dos horizontes nos 4 pontos mapeados (Sant Sebastian Bay, Guamaré, Paita District, Bertioga) para cada lateral/face da caixa, simultaneamente nos períodos de transformação das auroras e por do sol, no transcorrer da exposição. Espaço Quadrado, Paço das Artes, São Paulo, 2014. 


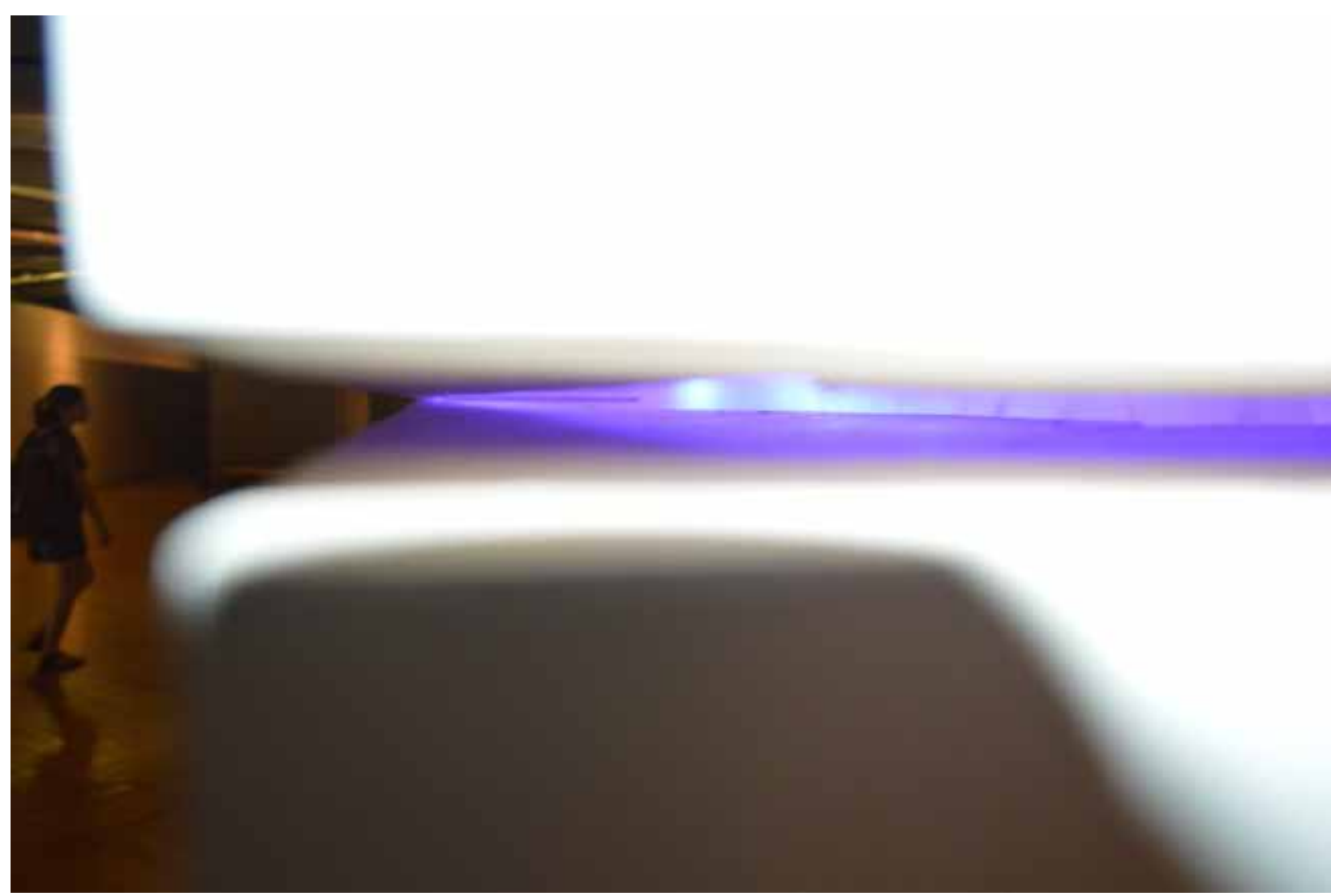

Figura 8 - Caixa dos Horizontes Possíveis, instalação interativa, 2014.

de avaliação e controle da energia" (HARTMAN, 2006, p.50) que em sua etimologia greco-latina significa sensibilidade a radiações, raios ou ondas (MENDONÇA, 2005, p.10) e é comumente conhecida como uma eficaz técnica rudimentar para encontrar água com a utilização de forquilhas e pêndulos. Nessa perspectiva, construímos uma antena para apontar e "neutralizar" os locais onde há uma variação energética, perceptível através da radiestesia. Neutralizar no sentido de reenviar, recircular essa energia que vem de baixo, compondo espaços de Zonas Neutras (ZNs) que nos indiquem que devemos parar e nos ater ao que nos circunda e não necessariamente ao que é explícito e visível.

Buscamos também apontar alguns caminhos da nossa metrópole invisível; caminhos subterrâneos que cortam as nossas cidades e que, às vezes, aparecem parcialmente para sumir de novo embaixo do asfalto; sinais de rios e córregos enterrados que para muita gente nem mais existem, mas que vão muito além do que é visível nas ruas, casas e avenidas.

Em nossas incursões na Zona Leste, pedimos aos moradores da região que segurassem as antenas nos locais onde fomos "descobrindo" água; agimos da mesma forma com a forquilha, para a qual buscamos nos arredores um galho de amoreira que foi retirado pelos "buscadores de água" Vô (Geraldo Francisco Ribeiro) e Jocimar Carlos Batista, nossos colaboradores especiais neste projeto que procederam à localização dos pontos de água naquela área.

A ideia consistiu em marcar alguns desses pontos e mapeá-los (com grafites e antenas) de maneira que ao circular por esses locais com o seu próprio celular, através de um aplicativo, fosse possível ao passante ir escutando o som de água do rio oculto que também vai passando bem ali, embaixo dos seus pés, devolvendo-o à percepção.

Coloca-se também a questão da escala desse enfrentamento, do sujeito nessa malha na construção de um sistema no qual ele também está incluído - que, hoje em dia, se efetiva de outra maneira, com portabilidade e mobilidade, levando os nós de uma rede, em outra camada possível de 


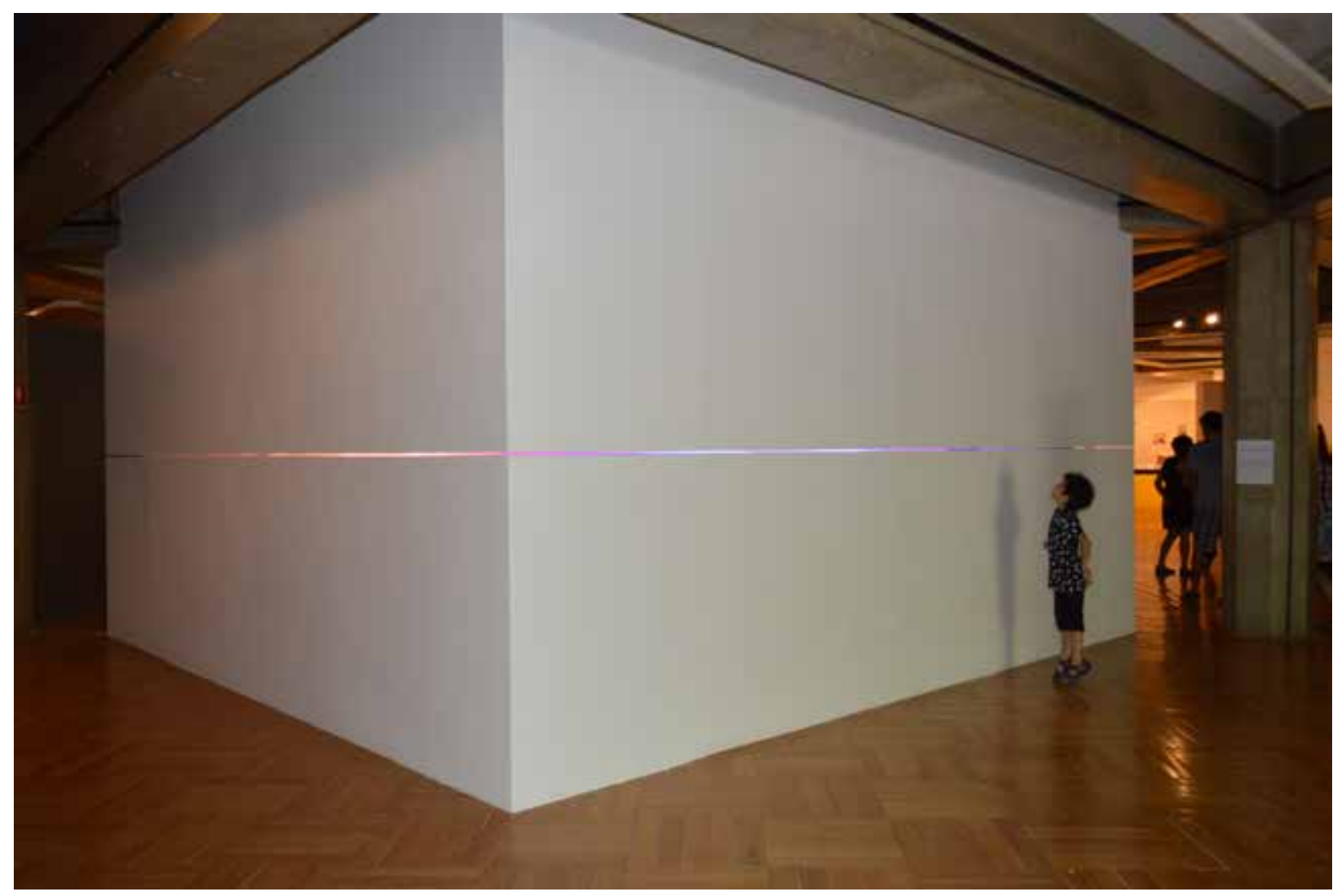

Figura 9 - Caixa dos Horizontes Possíveis, instalação interativa, exposição do Grupo Poéticas Digitais, Espaço Quadrado, Paço das Artes, São Paulo, 2014.

conexão de caminhos que se cruzam e se interpõem.

Na medida em que o sujeito se desloca, o seu raio de ação, de pertencimento, pode ser ativado por outros elementos. Podemos então pensar na permeabilidade desses espaços e de sua partilha, buscando uma abordagem mais poética da cidade que permita a troca, a descoberta, a criação e a experiência, recordando que "o ambiente a ser mapeado engloba ambos, os arredores imediatos, físicos, muitas vezes urbanos em que caminhamos, nossas próprias ações e percepções como pedestres, e o filtro cultural ou ideológico através do qual vemos essa experiência" (O'ROURKE, 2013). Trata-se de fazer o sujeito se sentir pertencente à rua, à praça, aos lugares, enfim, aos logradouros públicos, por mais que estes não disponham de uma grande infraestrutura, envolvendo-o numa condição de sintonia e compromisso em sua relação cotidiana com a cidade.

O Grupo Poéticas Digitais neste trabalho está composto por: Gilbertto Prado, Agnus Valente, Andrei Thomaz, Clarissa Ribeiro, Claudio Bueno,
Daniel Ferreira, Luciana Ohira, Nardo Germano, Renata La Rocca, Sérgio Bonilha e Tatiana Travisani.

Na sua configuração inicial, este projeto foi pensado para o Simpósio ZL Vórtice: Intervenções Urbanas - Laboratório, coordenado por Nelson Brissac Peixoto, Ary Perez, Gilbertto Prado e Ruy Lopes, no Centro Universitário Maria Antônia - USP. O evento aconteceu de março a junho de 2013, com mesas semanais compostas por quatro participantes. 0 trabalho "ZN:PRDM" foi apresentado em 19 de junho, na comunicação de Gilbertto Prado, com descrição de diversas etapas e procedimentos do projeto ${ }^{6}$.

\section{Caixa dos Horizontes Possíveis}

"Caixa dos Horizontes Possíveis" consiste em um cubo, espelhado verticalmente sobre o Espaço Quadrado do Paço das Artes, traçando uma fenda de luz que corta o espaço ao meio, de modo a configurar quatro horizontes suspensos na altura do olhar. 0 espectador pode se deslocar em torno dessa caixa fazedora de horizontes, levandonos para dentro e fora do espaço expositivo, aproximando-nos dos quatro pontos cardeais, 
onde a distância é percebida como uma linha que confunde o céu e o mar.

"Caixa dos Horizontes Possíveis" transforma o Espaço Quadrado, no Paço das Artes São Paulo, em possibilidade concreta de se olhar para fora do museu, da caixa, do cubo branco.

Cubo cortado por um horizonte artificial, mutável, a caixa convida à investigação, e ao mesmo tempo se mantém como obstáculo ao acesso efetivo. Operando entre a curiosidade e o minimalismo, ressignificando, antes de mais nada, o próprio espaço do Paço das Artes, os horizontes potenciais vão se alterando, acompanhando através de uma reconstrução artificial a luz de vários horizontes.

Partindo de uma interrupção no espaço (o Espaço Quadrado tem não só um muro que circunda, mas também um piso rebaixado em relação ao resto do edifício) e transformando a interrupção original em campo poético, "Caixa dos Horizontes Possíveis" cria um atrator, uma espécie de horizonte possível, potencial, reconfigurante, uma possibilidade de ver de algum modo através da fisicalidade do Paço, e, por que não, da própria obra.

Grupo Poéticas Digitais neste projeto esteve composto por Gilbertto Prado, Agnus Valente, Andrei Thomaz, Claudio Bueno, Ellen Nunes, Leonardo Lima, Luciana Ohira, Maria Luiza Fragoso, Maurício Trentin, Nardo Germano, Renata La Rocca e Sérgio Bonilha. O trabalho foi apresentado no Espaço Quadrado, no Paço das Artes São Paulo, como uma exposição individual do grupo, de 01/11 a 07/12/2014.

\section{NOTAS}

1. Viver é ir de um espaço para outro, tentando na medida do possível não bater em coisas. Tradução livre do autor.

2. Peter Anders propõe o termo "espaço cíbrido" para as novas relações de hibridizações e cibernética, onde hibridizam-se linguagens, conectam-se novos espaços e, dessa forma, o ambiente soma as propriedades do ciberespaço.

3. Texto de introdução ao seminário $Y+Y+Y$ Arte $y$ ciencias de la complejidad (Arteleku, $Y+Y+Y$ Arte y ciencias de la complejidadd. Acessos em 13 de novembro de 2012 no site http://www.arteleku.net/ programa-es $/ y-y-y$-ciencias-de-la-complejidad).
4. O dispositivo permite integrar e/ou hibridizar diversos elementos heterogêneos, possibilitando aos artistas maior liberdade em seus agenciamentos. Desse modo, o dispositivo pode ser tanto conceito da obra quanto instrumento de sua realização. Sobre o dispositivo, ver AnneMarie Duguet (2002).

5. Sobre este tema consultar Monachesi (2005) ou ainda Filipini dos Santos (2009).

6. Gilbertto Prado - Agenciamentos - ZI Vórtice. Produção: TAL - Televisión América Latina. Coordenação: Nelson Brissac Peixoto, Ary Peres, Gilbertto Prado, Ruy Lopes. São Paulo: CeUMA, 2013. Vídeo (29:27 min.), Son., widescreen, Color. Disponível em: <http://www.youtube.com/ watch?v=eas9zl-nZVw>. Acesso em: 24 jun. 2013.

\section{REFERÊNCIAS}

ANDERS, P. Toward an Architecture of Mind. In: CAiiA-STAR Symposium: 'Extreme parameters. New dimensions of interactivity. Barcelona: Universitat Oberta de Catalunya, 2001.

ARANTES, P. @rte e mídia: perspectivas da estética digital. São Paulo: Editora Senac, 2005.

CAMPOS JR., J. Depoimento, 20 mar. 2013. Entrevistadora: Cintia Leone. Produção: PodCast UNESP. São Paulo: PodAcqua, 2013. Áudio (3:35 min.). mp3. Entrevista concedida ao Canal PodAcqua do PodCast-UNESP. Disponível em: <http://podcast.unesp.br/podacqua-27032013podacqua-para-cada-ponto-de-enchenteem-sao-paulo-ha-um-rio-escondido-afirmageografo-paulistano.

COSTA, C. Questões de Arte. Editora Moderna: São Paulo, 2004.

COUCHOT, E. A tecnologia na arte: da fotografia à realidade virtual. Porto Alegre: Ed. UFRGS, 2003.

CUZZIOL, M. Desertesejo 2000 - Canteiro de Obras. Relatoria COELHO, Julia. In FREIRE, Cristina (Org.). Arte Contemporânea: Preservar o quê? Museeu de Arte Contemporânea de São Paulo, 2015, p. 161-166.

DUGUET, A-M. Déjouer l'image: Créations électroniques et numériques. Nîmes: Edition 
Jacqueline Chambon, 2002.

FOREST, F. Art et Internet. Paris: Editions Cercle d'Art, 2008.

GASPARETTO, D. A. (Org.). Arte-CiênciaTecnologia: o sistema da arte em perspectiva. Santa Maria, RS: Ed. Lab. Piloto, 2014. p. 111122. Disponível em <http://artedigitalbr.wix.com/ circuito\#!arte-cincia-tecnologia/cmls $>$. Acesso em: 12 fev. 2015.

HARTMAN, J. Radiônica e Radiestesia: Manual de trabalho com padrões de energia. São Paulo: Pensamento, 2006. p.50.

KAC, E. Telepresença e Bioarte: Humanos, coelhos e robôs em rede. São Paulo: EDUSP, 2013.

LATOUR, B.; HERMANT, E. Paris: Ville Invisible/ Paris: invisible city. Paris: Virtualbook, 1998.

MACHADO, A. O quarto iconoclasmo e outros ensaios Hereges. Editora Rios Ambiciosos: Rio de Janeiro, 2001.

MELLO, C. Extremidades do Vídeo. São Paulo: Senac, 2008.

Arte nas Extremidades.In Made

in Brasil: Três Décadas do Vídeo Brasileiro (org. Arlindo Machado). São Paulo: Itaú Cultural, 2003. p. 143-174.

Net Art. BIENAL DE SÃO PAULO, 25., 2002. Iconografias Metropolitanas - Brasil. Curador Agnaldo Farias. Catálogo... p. 162-184.

MENDONÇA, S. A Arte de curar pela radiestesia. 9. ed. São Paulo: Ed. Pensamento, 2005. p.10.

MÈREDIEU, F. Arts et nouvelles technologies: art vidéo, art numérique. Paris: Larousse, 2003.

MONACHESI, J. Acaso 30, Entrevista com Gilbertto Prado, Ars, ano 3, n.6, São Paulo, 2005. Disponível em: <http://www.scielo.br/scielo.php?script=sci arttext\&pid $=S 1678-53202005000200010\rangle$. Acesso em: 12 fev. 2015.

NUNES, F. O. Desertesejo: partilha e simulação, Revista Texto Digital, UFSC, ano 5, n.2, 2009. Disponível em <https://periodicos.ufsc.br/ index.php/textodigital/article/view/18079288.2009v5n2p112/13189>. Acesso em: 12 fev. 2015.
O'ROURKE, K. Walking and Mapping: artists as cartographers. Massachussetts: MIT Press, 2013.

City Portraits: An Experience in the Interactive Transmission of Imagination. Leonardo, v. 24, n. 2, 1991, p. 215-219.

PEREC, G. Espèces d'espaces, Paris: Galilée, 1974.

POPPER, F. L'art à l'âge électronique. Paris: Editions Hazan, 1993.

PRADO, G. Arte telemática: dos intercâmbios pontuais aos ambientes virtuais multiusuário. São Paulo, SP: Itaú Cultural, 2003.

Artistic Experiments on Telematic Nets: Recent Experiments in Multiuser Virtual Environments in Brazil. In: OLATS/Observatoire Leonardo des Arts et des Techno-Sciences. Paris, 2003. Disponível em <http://www.olats. org/projetpart/artmedia/2002/t_gPrado.html>. Acesso em: 12 fev. 2015.

Arte et Télématique. Les Cahiers du Collège Iconique, Communications et débats, n. XVIII, Paris: INA, 2006. p. 1-39. Disponível em <http://www2.eca.usp.br/cap/gilbertto/ textos 20publica/20101209 20Mais 20 dois/2006-Arte_et_Telematique.pdf $>$. Acesso em: 12 fev. 2015.

Audiovisual, n. 1, Edição especial A Era Digital e seus Desdobramentos Estéticos, UFSCar, 2008, p. 1 -10. Disponível em <http:// www.rua.ufscar.br/redes-e-ambientes-virtuaisartisticos/>. Acesso em: 12 fev. 2015.

Algumas experiências de arte em rede: projetos WAwRwT, colunismo e desertesejo, Porto Arte, v. 17, n. 28, 2010a-Dossiê.

Grupo Poéticas Digitais: projetos desluz e amoreiras. ARS (São Paulo), São Paulo, v. 8, n. 16, 2010b, p. 110-125. Disponível em <http://www.scielo.br/scielo.php?script $=$ sci $_{-}$ arttext\&pid=S1678-53202010000200008\&lng= pt\&nrm=iso >. Acesso em: 12 fev. 2015.

Digital Art, Dialogues and Process. In: MAGALHÃES, Ana Gonçalves; BEIGUELMAN, Giselle (Org.). Possible Futures: Art, Museums And Digital Archives. São Paulo: Ed. Peirópolis, 2013a. p. 114-128. 
Projetos recentes do Grupo Poéticas

Digitais. In: SARAIVA, Alberto (Org.). Poesia

Visual. Rio de Janeiro: F10 Editora - Oi Futuro, 2013b. p. 14-21.

. Projetos "Encontros" e "ø25 -

QUARTO LAGO" do Grupo Poéticas Digitais.

Revista Visualidades, v. 12, n. 2, 2014a, Goiania: UFG, p. 9-19. Disponível em <https:// www.academia.edu/11414347/Revista Visualidades_v._12_n._2_2014_>. Acesso em: 19 nov. 2015.

. Projetos recentes do Grupo Poéticas Digitais: 2010/2012. ARJ Brasil, v. 1/2, Jul./Dez. 2014b, p. 39-58. Disponível em <http://www. periodicos.ufrn.br/artresearchjournal/article/ view/5362>. Acesso em: 12 fev. 2015.

PRADO, G.; NUNES, F. O. Ligue-se no website da MTV. In: PEDROSO, Maria Goretti; MARTINS, Rosana (Org.). Admirável mundo: MTV Brasil. São Paulo: Saraiva, 2006. p.156-163.

SANTOS, F. Arte Contemporânea em Diálogo com as Mídias Digitais: concepção artística/ curatorial e crítica. Santa Maria: Editora Pallotti, 2009.

ZANINI, W. A Arte da Comunicação telemática - a interatividade no cibersepaço. Ars, ano 1, n.1, São Paulo: ECA/USP, 2003, p. 11-34.

\section{Sobre o autor}

Gilbertto Prado, artista multimídia e coordenador do Grupo Poéticas Digitais. Estudou Artes e Engenharia na Unicamp e o doutorado em Artes na Universidade Paris I - Panthéon Sorbonne, em 1994. Tem realizado e participado de inúmeras exposições no Brasil e no exterior. Recebeu o 9) Prix Möbius International des Multimédias, Beijin, 2001; Prêmio Rumos, 2000, Transmídia, 2002 Itaú Cultural; e o 6) Prêmio Sergio Motta de Arte e Tecnologia, 2006; entre outros. Trabalha com arte em rede e instalações interativas. Atualmente é Professor dos Programas de Pós-Graduação em Artes Visuais da ECA - USP e do PPG Design da Universidade Anhembi Morumbi. www. gilberttoprado.net. 